\title{
Catshark egg capsules from a Late Eocene deep-water methane-seep deposit in western Washington State, USA
}

Steffen Kiel, Jörn Peckmann, and Klaus Simon

Acta Palaeontologica Polonica 58 (1), 2013: 77-84 doi: http://dx.doi.org/10.4202/app.2011.0077

Fossil catshark egg capsules, Scyliorhinotheca goederti gen. et sp. nov., are reported from a Late Eocene deep-water methane-seep calcareous deposit in western Washington State, USA. The capsules are preserved three-dimensionally and some show mineralized remnants of the ribbed capsule wall consisting of small globular crystals that are embedded in a microsparitic matrix. The globules are calcitic, but a strontium content of 2400-3000 ppm suggests that they were originally

aragonitic. The carbonate enclosing the egg capsules, and the capsule wall itself, show $\delta^{13} \mathrm{C}$ values as low as $-36.5 \%$, suggesting that formation was induced by the anaerobic oxidation of methane and hence in an anoxic environment. We put forward the following scenario for the mineralization of the capsule wall: (i) the collagenous capsules experienced a sudden change from oxic to anoxic conditions favouring an increase of alkalinity; (ii) this led to the precipitation of aragonitic globules within the collagenous capsule wall; (iii) subsequently the remaining capsule wall was mineralized by calcite or aragonite; (iv) finally the aragonitic parts of the wall recrystallized to calcite. The unusual globular habit of the early carbonate precipitates apparently represents a taphonomic feature, resulting from mineralization mediated by an organic matrix. Taphonomic processes, however, are at best contributed to an increase of alkalinity, which was mostlydriven by methane oxidation at the ancient seep site.

Key words: Elasmobranchia, Scyliorhinidae, taphonomy, exceptional preservation, collagen, Late Eocene, Washington State, USA.

Steffen Kiel [skiel@uni-goettingen.de] Georg-August Universität Göttingen, Geowissenschaftliches Zentrum, Abteilung Geobiologie and Courant Research Center Geobiology, Goldschmidtstr. 3, 37077

Göttingen, Germany; Jörn Peckmann [joern.peckmann@univie.ac.at], Universität Wien, Erdwissenschaftliches Zentrum, Department für Geodynamik und Sedimentologie, Althanstr. 14, 1090 Wien, Austria; Klaus Simon [ksimon@gwdg.de], Georg-August Universität Göttingen, Geowissenschaftliches Zentrum, Abteilung Geochemie, Goldschmidtstr. 1, 37077 Göttingen, Germany. 
This is an open-access article distributed under the terms of the Creative Commons

Attribution License (for details please see creativecommons.org), which permits unrestricted use, distribution, and reproduction in any medium, provided the original author and source are credited.

FoF 